\title{
Untargeted Metabolomics Analysis by UHPLC-MS/MS of Soybean Plant in a Compatible Response to Phakopsora pachyrhizi Infection
}

\author{
Evandro Silva ${ }^{1}{ }^{(}$, José Perez da Graça ${ }^{2}{ }^{(}$, Carla Porto ${ }^{1,3}$, Rodolpho Martin do Prado ${ }^{1}{ }^{(}$, Estela Nunes ${ }^{4}(\mathbb{D}$, \\ Francismar Corrêa Marcelino-Guimarães ${ }^{2}\left[\right.$, Mauricio Conrado Meyer ${ }^{2}{ }^{(1)}$ and Eduardo Jorge Pilau ${ }^{1, *(1)}$ \\ 1 Laboratory of Biomolecules and Mass Spectrometry, Department of Chemistry, State University of Maringá, \\ 5790, Colombo Av, Maringá 87020-080, PR, Brazil; evandroas20@gmail.com (E.S.); \\ cporto.silva@gmail.com (C.P.); pradorodolpho@gmail.com (R.M.d.P.) \\ 2 Brazilian Agricultural Research Corporation Soybean, Carlos João Strass Rd, Londrina 86001-970, PR, Brazil; \\ perezparr@gmail.com (J.P.d.G.); francismar.marcelino@embrapa.br (F.C.M.-G.); \\ mauricio.meyer@embrapa.br (M.C.M.) \\ 3 MsBioscience, Quintino Bocaiúva 298, Street, Maringá 87020-160, PR, Brazil \\ 4 Brazilian Agricultural Research Corporation Swine \& Poultry, BR-153, Km 110 Rd, \\ Concórdia 89715-899, SC, Brazil; estela.nunes@embrapa.br \\ * Correspondence: ejpilau@uem.br
}

Citation: Silva, E.; Perez da Graça, J.; Porto, C.; Martin do Prado, R.; Nunes, E.; Corrêa Marcelino-Guimarães, F.; Conrado Meyer, M.; Jorge Pilau, E. Untargeted Metabolomics Analysis by UHPLC-MS/MS of Soybean Plant in a Compatible Response to Phakopsora pachyrhizi Infection. Metabolites 2021, 11, 179. https:// doi.org/10.3390/metabo11030179

Academic Editor:

Thusitha W. Rupasinghe

Received: 7 December 2020

Accepted: 16 February 2021

Published: 19 March 2021

Publisher's Note: MDPI stays neutral with regard to jurisdictional claims in published maps and institutional affiliations.

Copyright: (c) 2021 by the authors. Licensee MDPI, Basel, Switzerland. This article is an open access article distributed under the terms and conditions of the Creative Commons Attribution (CC BY) license (https:/ / creativecommons.org/licenses/by/ $4.0 /)$.

\begin{abstract}
Phakopsora pachyrhizi is a biotrophic fungus, causer of the disease Asian Soybean Rust, a severe crop disease of soybean and one that demands greater investment from producers. Thus, research efforts to control this disease are still needed. We investigated the expression of metabolites in soybean plants presenting a resistant genotype inoculated with P. pachyrhizi through the untargeted metabolomics approach. The analysis was performed in control and inoculated plants with P. pachyrhizi using UHPLC-MS/MS. Principal component analysis (PCA) and the partial least squares discriminant analysis (PLS-DA), was applied to the data analysis. PCA and PLS-DA resulted in a clear separation and classification of groups between control and inoculated plants. The metabolites were putative classified and identified using the Global Natural Products Social Molecular Networking platform in flavonoids, isoflavonoids, lipids, fatty acyls, terpenes, and carboxylic acids. Flavonoids and isoflavonoids were up-regulation, while terpenes were down-regulated in response to the soybean-P. pachyrhizi interaction. Our data provide insights into the potential role of some metabolites as flavonoids and isoflavonoids in the plant resistance to ASR. This information could result in the development of resistant genotypes of soybean to P. pachyrhizi, and effective and specific products against the pathogen.
\end{abstract}

Keywords: Asian soybean rust; soybean; metabolomics; UHPLC-MS/MS; chemometrics; GNPS; Phakopsora pachyrhizi

\section{Introduction}

Soybean (Glycine max (L.) Merrill) is one of the most important economic and oil crops worldwide. The major significances of soybean are related to their great nutritional value both to humans and livestock and are used to produce renewable fuels [1,2]. However, soybean crop yield is largely affected by several diseases. Asian soybean rust (ASR) disease alone was estimated to cause $10 \%$ yield losses in the north-central United States and $50 \%$ or greater in the south-eastern United States [3]. Losses can be as high as $90 \%$ when climatic conditions favor pathogens reproduction [4]. The ASR is caused by the Phakopsora pachyrhizi pathogen, a biotrophic fungus that can establish itself at any stage of plant development [5]. Measures to control fungal growth are centered on the use of fungicides. However, there is a growing concern about the use of such fungicides due to environmental impact, human health, and the appearance of resistant P. pachyrhizi strains [6]. The constant use of triazole 
and strobilurin fungicides, for example, has resulted in the development of increased tolerance in P. pachyrhizi populations [7].

Another way to fight the disease is through the use of resistant cultivars. Seven dominant resistance to Phakopsora pachyrhizi (Rpp1-Rpp7) loci, have been identified mapped at different loci for conferring immunity (without visible symptoms) or incomplete resistance which is more common than immunity. Incomplete resistance is characterized by the development of reddish-brown lesions (RB) with reduced sporulation to specific pathogen isolates [8-10]. However, the Rpp genes confer resistance to only a limited set of specific P. pachyrhizi isolates, and these single gene sources are not durable when used in the field, due to pathogen variability [11].

Plants have mechanisms to recognize pathogens via pathogen-associated molecular patterns (PAMPs) and prevent their development using various defensive mechanisms [12]. However, pathogens can bypass these mechanisms and propagate through the plant [13]. Plant defensive options can be the modulation of primary and secondary metabolism [14]. For example, stressed plants will produce hormones, such as salicylic acid (SA), jasmonic acid (JA), and ethylene (ET), which activate plant defense genes causing changes in metabolic pathways that produce a great diversity of secondary metabolites defense $[15,16]$.

Untargeted metabolomics is an analytical approach employed to identify as many metabolites as possible in a given sample, which can be used to understand plant-pathogen interactions [17]. Plant specimens are complex matrices composed of a myriad of metabolites. Thus, analytical methods based on mass spectrometry (MS) should be encouraged to identify and quantify such metabolites [18]. Moreover, the MS technique provides high sensitivity, resolution, detection, and precision [19]. The coupling of liquid chromatography to mass spectrometry is used to further resolve the complexity of samples via a prior separation, thus improving the detection of the metabolites. This ensures relatively high sensitivity, repeatability, and selectivity [20].

One of the drawbacks of using ultra-high-performance liquid chromatography coupled to high-resolution mass spectrometry (UHPLC-MS/MS) is the massive amount of data generated. Tools to assist data organization, processing, and metabolite annotation are often used to assist and reduce time in the data mining stage. Of those, chemometric strategies are widely explored to extract relevant information from a data set. Multivariate analysis methods, such as principal component analysis (PCA) and the partial least squares discriminant analysis (PLS-DA), where the molecular features that contribute most to the variation or separation are identified for further analysis, are the most used in the field of metabolomics [21]. Both methods describe a set of variables measured in a set of individuals in a more condensed form, this is obtained by projecting the data in a reduced space so that it represents as much of the original information as possible [22].

For the metabolite annotation, selected by the chemometric analysis, emerging approaches to computational analysis based on MS should be employed, such as Molecular Networking based on fragmentation mass spectra (MS/MS). The MS/MS spectra are compared with reference spectra on the Global Social Natural Products Molecular Networking (GNPS) platform to annotate molecules and discover putative analogs [23]. We previously reported the metabolomics of a soybean genotype susceptible to P. pachyrhizi using mass spectrometry combined with the Molecular Networking tool. The results revealed a significant production of secondary defense metabolites in the plant infected by P. pachyrhizi, which originated from the phenylpropanoid and flavonoid pathways [24]. In this study, we performed an untargeted metabolomics analysis of a soybean plant containing the Rpp3 gene [25], that shows incomplete resistance with RB-type lesion, in response to infection by P. pachyrhizi. In this case, liquid chromatography coupled to mass spectrometry (UHPLC-MS/MS), integrated with multivariate analysis and Molecular Networking were employed to elucidate changes in metabolic profiles related to plant defense responses. The results can identify metabolic pathways involved in the systemic induced resistance against 
infection by P. pachyrhizi, in plants of Rpp3 gene, providing subsidies for the unveiling of defense mechanisms of the plant, and the production of new lines of resistant soybean.

\section{Results}

\subsection{Visual Observation of Symptoms}

First, the changes in metabolism in the soybean plant when they were inoculated or not by P. pachyrhizi after 14 days post-inoculation were evaluated. This period was sufficient for the pathogen to infect the leaves of the plant (spots and color changes), therefore, comparisons of the metabolome between the groups of control and inoculated plants could be evaluated. The initial symptoms of the disease are seen on the back of the leaf and are characterized by spots darker than the leaf tissue (Supplementary Figure S1) compared to the leaf tissue of a healthy plant, with a corresponding protuberance (Supplementary Figure S2), lesion known as uredinia [26]. The spores of the fungus are produced in the uredinia, which can be seen five to eight days after infection. Plant genotypes resistant to ASR show RB lesions, with reduced levels of sporulation of uredias in the lesions. (Supplementary Figure S1), while susceptible genotypes have tan-colored lesions (TAN) and are characterized by the increased formation of uredias.

\subsection{UHPLC-ESI(+)-MS/MS Analysis}

The UHPLC-ESI(+)-MS/MS technique was employed to evaluate the metabolite profile of soybean plants inoculated or not with P. pachyrhizi spores and to obtain the largest number of significant metabolites in the plant-pathogen interaction. Chromatograms were obtained in triplicate from UHPLC-ESI-(+)-MS/MS analysis for each plant, totaling 18 chromatograms for control plants and 18 chromatograms for inoculated plants (Supplementary Figure S3).

The MS chromatograms indicated different metabolic profiles in comparison with inoculated and non-inoculated plants. Base peak chromatograms (BPC) showed differences in chromatographic peaks (absence/presence and intensities) between the retention time interval 5.0-12.5 min (Supplementary Figure S3). However, only the visual inspection of $\mathrm{BPC}$ is not enough to discriminate changes in plant metabolism that occurred after infection by the pathogen. For this reason, chemometric analyses were used in the UHPLC-ESI(+)MS/MS data.

\subsection{Data Processing and Chemometric Analysis}

The data matrix of molecular features $(\mathrm{rt}, \mathrm{m} / \mathrm{z}$ ) was obtained after pre-processing the data and exported to the MetaboAnalyst 3.0 online software for the use of multivariate analyses. The first analysis was performed by using PCA, an unsupervised method usually employed to determine patterns between multivariate samples. The PCA analysis showed a clear tendency of separation between the data set of samples from control plants and inoculated with the pathogen (Figure 1A), thus reflecting differential metabolic characteristics in these two groups. It was also possible to observe that the PCA analysis was reproductive for each plant (Figure 1B). The first main component (PC1) explained $17.0 \%$ of the total variability of the data set while the second main component (PC2) explained $12.8 \%$ of the total variability of the data set.

For a better understanding of the metabolic characteristics and interpretation of the results obtained by the unsupervised analysis model, the PLS-DA method was applied. The method consists of highlighting specific similarities or differences between the samples, preferably organizing the main components that have relationships between important variables and can be specific to the group of interest. Besides, statistics such as variable importance in the projection (VIP) obtained by the PLS-DA method and can be used to select the most important variables, [27] allowing the identification of characteristics of the metabolites responsible for the discrimination between classes or groups. 
A

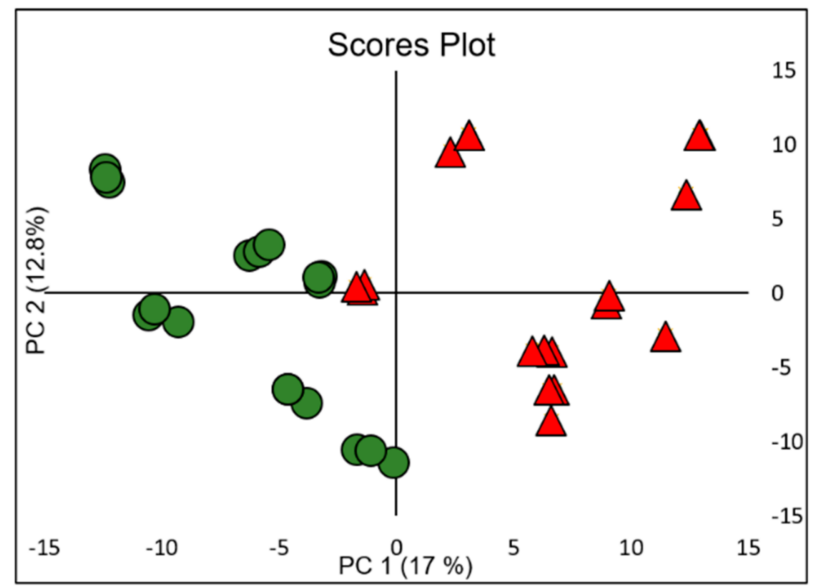

C $\Delta$ I
B

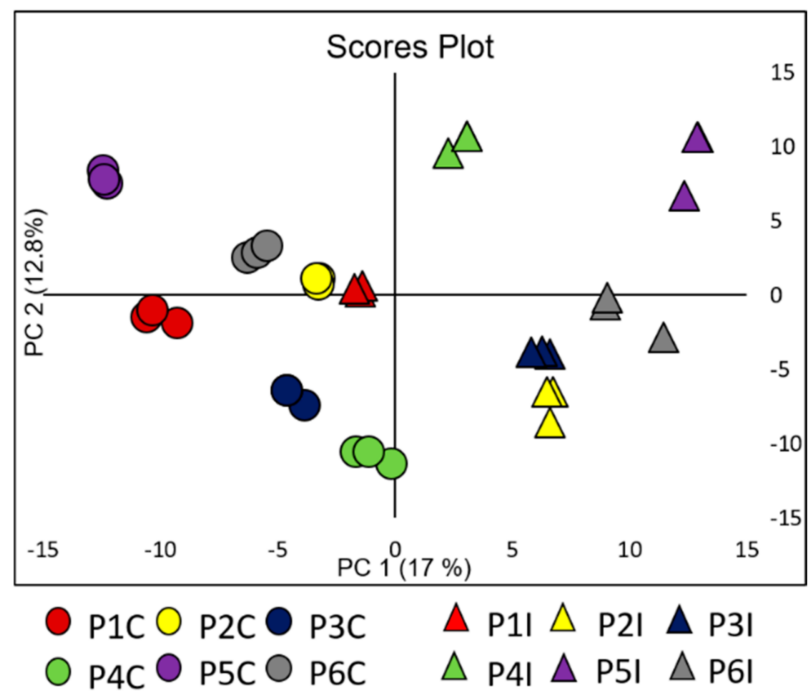

Figure 1. Unsupervised chemometric modeling (UHPLC-ESI-(+)-MS/MS data): (A) PCA scores of 18 samples (triplicate of 6 control plants and 6 inoculated plants), green circles correspond to control plant samples (C), red triangle corresponds to inoculated plant samples (I). (B) The scores plot in (A) but colored according to triplicate each plant (P). 5 PCs explained $51.6 \%$ of the total data variance.

The PLS-DA analysis (Figure 2), revealed the clear separation between the data set of the samples from control and inoculated plants by PLS-DA analysis. PLS-DA models obtained for the data set were evaluated using Leave one out cross-validation (LOOCV). The LOOCV consists of choosing one of the samples to compose the validation set and the other samples are used for the training set. A new sample is taken to compose the validation set and the sample that was used previously for the validation set this time will constitute the training set, these operations are repeated several times until all samples have been part of the validation set at least once [28].

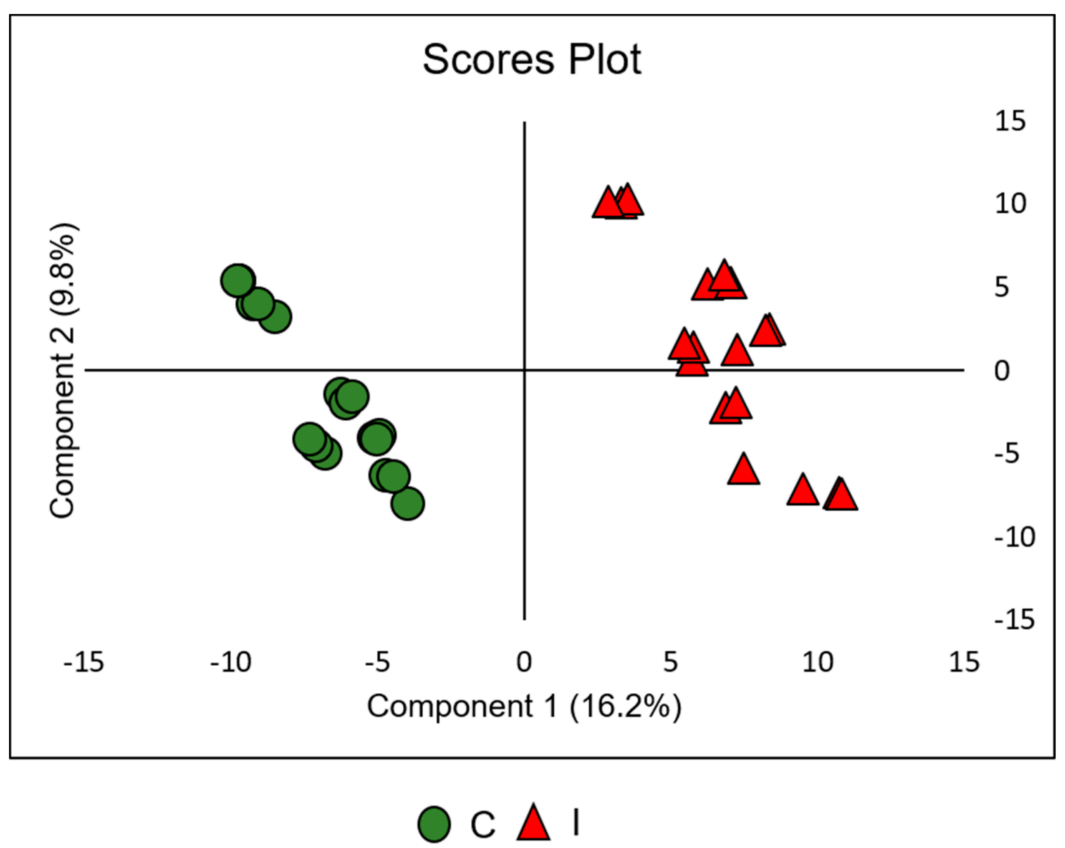

Figure 2. Partial least-squares discriminant analysis (PLS-DA) of 18 samples (triplicate of 6 control plants and 6 inoculated plants), green circles correspond to control plant samples (C), red circles correspond to inoculated plant samples (I). The classification model was built to screen potential biomarkers using VIP values. 
Three parameters were used to validate the model, precision that describes how close to a true value measurement, $R^{2}$ that measures the quality of the fit, and $Q^{2}$ that measures the predictive capacity of the model. The values obtained by cross-validation were: precision $=1.00, R^{2}=0.99 Q^{2}=0.96$, these values represent a great performance for the model created with the data sets. VIP values $\geq 1$ detected in the PLS-DA analysis associated with $p$-value data $\leq 0.001$ (Welch $t$-test) were used for the selection of molecular features, which show a significant contribution to the observed clustering. Thirty-seven variables were selected as the most significant for the discrimination of the groups (Supplementary Table S1).

Despite the excellent values obtained by cross-validation demonstrating great precision, the model created cannot be used as a classification model for external samples because many of the variables used in the construction of this model have low intensities. These variables may be absent in external samples and lead to an incorrect classification. Thus, a new model using only the selected variables (Supplementary Table S1) with the most significant was created (Supplementary Figure S4A). The values obtained by crossvalidation were: precision $=1.00, R^{2}=0.99 Q^{2}=0.99$, presenting a performance similar to the previous model. The validation of the model was performed through permutation tests (Supplementary S4B and S4C), with 2.000 repetitions for both tests. The probability that the model was created by chance was less than $0.0005 \%$, showing a level of confidence that the separations are caused by the differences between the samples of control and inoculated plants. Thus, by reducing the number of non-significant variables in the model, it can overall be used as a classification strategy in further studies.

\subsection{Chemical Classification and Identification of Metabolites by the GNPS Platform}

The GNPS Molecular Networking platform was carried out to organize UHPLC-ESI (+)-MS/MS data and to obtain information on the molecular characteristics selected from the static and multivariate analysis through putative chemical classification (Supplementary Table S1). The MN tool correlates MS/MS spectra according to the similarity of fragmentation patterns of related precursor ions. In this way, the related compounds through their fragmentation profiles are grouped in clusters represented by a node, providing better visualization of the data and decreasing the data mining time of untargeted metabolomics studies. The analysis of the chemical map highlights structurally related compounds and, when comparing the MS/MS spectra with databases of the platform, facilitates the process of chemical classification and identification of the compounds.

The MolNetEnhancer analysis available on the GNPS platform was applied to the generated MN. MolNetEnhancer is a workflow that allows chemical annotation, visualization, and discovery of the subtle diversity of structures in molecular families [29]. The analysis combines complementary molecular mining tools with the MN network, such as the in silico annotation tool, network annotation propagation (NAP), and MS2LDA [30,31].

Once chemical compounds detected from the control plants and inoculated with P. pachyrhizi were combined, a total of 1.627 nodes (consensus spectra) were obtained in the MN (Supplementary Figure S5). Of these, 301 (18.5\%) consensus spectra (brown nodes) were obtained exclusively when P. pachyrhizi was inoculated in soybean plants, 190 (11.8\%) consensus spectra (green nodes) were obtained for plants in the control group, and 1.137 $(69.8 \%)$ consensus spectra (gray nodes) obtained for both groups. Sixty-seven consensus spectra (black bold border nodes) were compatible with the GNPS library (4.18\% of the total) which were manually confirmed with the MS/MS spectra (data not shown) through fragment ions and mass error, ranged from 0.0 to $6.7 \mathrm{ppm}$ (Table 1). 
Table 1. Metabolites are putatively identified in soybean plants.

\begin{tabular}{|c|c|c|c|c|}
\hline Putative Metabolite Identification & Molecular Formula & $\begin{array}{c}{[\mathrm{M}+\mathrm{H}]^{+}} \\
\text {Measured }\end{array}$ & $\begin{array}{c}{[\mathbf{M}+\mathbf{H}]^{+}} \\
\text {Theoretical }\end{array}$ & $\begin{array}{l}\text { Mass Accuracy } \\
\text { (ppm) }\end{array}$ \\
\hline \multicolumn{5}{|l|}{ Amino acid } \\
\hline Proline & $\mathrm{C}_{5} \mathrm{H}_{9} \mathrm{NO}_{2}$ & 116.0704 & 116.0706 & -1.7 \\
\hline Pipecolic acid & $\mathrm{C}_{6} \mathrm{H}_{11} \mathrm{NO}_{2}$ & 130.0861 & 130.0863 & -1.5 \\
\hline Leucine & $\mathrm{C}_{6} \mathrm{H}_{13} \mathrm{NO}_{2}$ & 132.1020 & 132.1019 & 0.8 \\
\hline Phenylalanine & $\mathrm{C}_{9} \mathrm{H}_{11} \mathrm{NO}_{2}$ & 166.0859 & 166.0863 & -2.4 \\
\hline Tyrosine & $\mathrm{C}_{9} \mathrm{H}_{11} \mathrm{NO}_{3}$ & 182.0807 & 182.0812 & -2.7 \\
\hline Tryptophan & $\mathrm{C}_{11} \mathrm{H}_{12} \mathrm{~N}_{2} \mathrm{O}_{2}$ & 205.0964 & 205.0972 & -3.9 \\
\hline \multicolumn{5}{|l|}{ Phenylpropanoids } \\
\hline p-Coumaric acid & $\mathrm{C}_{9} \mathrm{H}_{8} \mathrm{O}_{3}$ & 165.0541 & 165.0546 & -3.0 \\
\hline Citric acid & $\mathrm{C}_{6} \mathrm{H}_{8} \mathrm{O}_{7}$ & 193.0337 & 193.0343 & -3.1 \\
\hline Ferulic acid & $\mathrm{C}_{10} \mathrm{H}_{10} \mathrm{O}_{4}$ & 195.0647 & 195.0642 & 2.6 \\
\hline Abscisic acid & $\mathrm{C}_{15} \mathrm{H}_{20} \mathrm{O}_{4}$ & 265.1425 & 265.1434 & -3.4 \\
\hline \multicolumn{5}{|l|}{ Peptides } \\
\hline Ile-Pro & $\mathrm{C}_{11} \mathrm{H}_{20} \mathrm{~N}_{2} \mathrm{O}_{3}$ & 229.1542 & 229.1546 & -1.7 \\
\hline Ile-Val & $\mathrm{C}_{11} \mathrm{H}_{22} \mathrm{~N}_{2} \mathrm{O}_{3}$ & 231.1700 & 231.1703 & -1.3 \\
\hline Leu-Leu & $\mathrm{C}_{12} \mathrm{H}_{24} \mathrm{~N}_{2} \mathrm{O}_{3}$ & 245.1855 & 245.1859 & -1.6 \\
\hline Leu-Asn & $\mathrm{C}_{10} \mathrm{H}_{19} \mathrm{~N}_{3} \mathrm{O}_{4}$ & 246.1439 & 246.1448 & -3.7 \\
\hline Asp-Leu & $\mathrm{C}_{10} \mathrm{H}_{18} \mathrm{~N}_{2} \mathrm{O}_{5}$ & 247.1279 & 247.1288 & -3.6 \\
\hline Pro-Phe & $\mathrm{C}_{15} \mathrm{H}_{22} \mathrm{~N}_{2} \mathrm{O}_{3}$ & 263.1412 & 263.1390 & 8.4 \\
\hline Phe-Val & $\mathrm{C}_{14} \mathrm{H}_{20} \mathrm{~N}_{2} \mathrm{O}_{3}$ & 265.1543 & 265.1546 & -1.1 \\
\hline Leu-Phe & $\mathrm{C}_{14} \mathrm{H}_{18} \mathrm{~N}_{2} \mathrm{O}_{3}$ & 279.1694 & 279.1703 & -3.2 \\
\hline Asn-Phe & $\mathrm{C}_{13} \mathrm{H}_{17} \mathrm{~N}_{3} \mathrm{O}_{4}$ & 280.1292 & 280.1291 & 0.4 \\
\hline Leu-Leu-Gly & $\mathrm{C}_{14} \mathrm{H}_{27} \mathrm{~N}_{3} \mathrm{O}_{4}$ & 302.2067 & 302.2074 & -2.3 \\
\hline Peptide & $\mathrm{C}_{15} \mathrm{H}_{27} \mathrm{~N}_{3} \mathrm{O}_{4}$ & 314.2066 & 314.2074 & -2.5 \\
\hline Leu-Val-Val & $\mathrm{C}_{16} \mathrm{H}_{31} \mathrm{~N}_{3} \mathrm{O}_{4}$ & 330.2377 & 330.2387 & -3.0 \\
\hline Leu-Leu-Val & $\mathrm{C}_{17} \mathrm{H}_{33} \mathrm{~N}_{3} \mathrm{O}_{4}$ & 344.2533 & 344.2543 & -2.9 \\
\hline \multicolumn{5}{|l|}{ Cumarin } \\
\hline 7-Methoxycoumarin & $\mathrm{C}_{10} \mathrm{H}_{8} \mathrm{O}_{3}$ & 177.0541 & 177.0546 & -2.8 \\
\hline Scopoletin & $\mathrm{C}_{10} \mathrm{H}_{8} \mathrm{O}_{4}$ & 193.0488 & 193.0495 & -3.6 \\
\hline Xanthyletin & $\mathrm{C}_{14} \mathrm{H}_{12} \mathrm{O}_{3}$ & 229.0857 & 229.0859 & -0.9 \\
\hline Osthole & $\mathrm{C}_{15} \mathrm{H}_{16} \mathrm{O}_{3}$ & 245.1168 & 245.1172 & -1.6 \\
\hline \multicolumn{5}{|l|}{ Flavonoids } \\
\hline Daidzin & $\mathrm{C}_{21} \mathrm{H}_{20} \mathrm{O}_{9}$ & 417.1195 & 417.1180 & 3.6 \\
\hline Daidzein & $\mathrm{C}_{15} \mathrm{H}_{10} \mathrm{O}_{4}$ & 255.0650 & 255.0651 & -0.4 \\
\hline Neobavaisoflavone & $\mathrm{C}_{20} \mathrm{H}_{18} \mathrm{O}_{4}$ & 323.1273 & 323.1278 & -1.5 \\
\hline Sojagol & $\mathrm{C}_{20} \mathrm{H}_{16} \mathrm{O}_{5}$ & 337.1067 & 337.1070 & -0.9 \\
\hline Isoflavonoid & $\mathrm{C}_{21} \mathrm{H}_{20} \mathrm{O}_{4}$ & 337.1430 & 337.1434 & -1.2 \\
\hline Gliceollin I & $\mathrm{C}_{20} \mathrm{H}_{18} \mathrm{O}_{5}$ & 339.1217 & 339.1227 & -2.9 \\
\hline Gliceollin II & $\mathrm{C}_{20} \mathrm{H}_{18} \mathrm{O}_{5}$ & 339.1222 & 339.1227 & -1.5 \\
\hline Gliceollin III & $\mathrm{C}_{20} \mathrm{H}_{18} \mathrm{O}_{5}$ & 339.1220 & 339.1227 & -2.1 \\
\hline Isoflavonoid & $\mathrm{C}_{21} \mathrm{H}_{18} \mathrm{O}_{5}$ & 351.1219 & 351.1227 & -2.3 \\
\hline Isoflavonoid & $\mathrm{C}_{21} \mathrm{H}_{20} \mathrm{O}_{5}$ & 353.1377 & 353.1383 & -1.7 \\
\hline Xanthohumol & $\mathrm{C}_{21} \mathrm{H}_{22} \mathrm{O}_{5}$ & 355.1534 & 355.1540 & -1.7 \\
\hline 7-O-Methylluteone & $\mathrm{C}_{21} \mathrm{H}_{20} \mathrm{O}_{6}$ & 369.1330 & 369.1333 & -0.7 \\
\hline Schizandrin C & $\mathrm{C}_{22} \mathrm{H}_{24} \mathrm{O}_{6}$ & 385.1638 & 385.1645 & -1.8 \\
\hline Genistin & $\mathrm{C}_{21} \mathrm{H}_{20} \mathrm{O}_{10}$ & 433.1118 & 433.1129 & -2.5 \\
\hline Luteolin 8-C-glucoside & $\mathrm{C}_{21} \mathrm{H}_{21} \mathrm{O}_{11}$ & 449.1067 & 449.1078 & -2.4 \\
\hline Isoquercitin & $\mathrm{C}_{21} \mathrm{H}_{20} \mathrm{O}_{12}$ & 465.1020 & 465.1027 & -1.5 \\
\hline $\begin{array}{l}\text { 3'-O-methyltricetin } \\
\text { 3-O- } \alpha \text {-L-rhamnopyranoside }\end{array}$ & $\mathrm{C}_{22} \mathrm{H}_{22} \mathrm{O}_{12}$ & 479.1170 & 479.1184 & -2.9 \\
\hline Kaempferol-O-acetylhexoside & $\mathrm{C}_{23} \mathrm{H}_{22} \mathrm{O}_{12}$ & 491.1163 & 491.1184 & -4.3 \\
\hline Malonyldaidzin & $\mathrm{C}_{24} \mathrm{H}_{22} \mathrm{O}_{12}$ & 503.1174 & 503.1184 & -2.0 \\
\hline $\begin{array}{c}\text { Formononetin } \\
\text { 7-O-glucoside-6"'"-O-malonate }\end{array}$ & $\mathrm{C}_{25} \mathrm{H}_{24} \mathrm{O}_{12}$ & 517.1339 & 517.1341 & -0.3 \\
\hline Malonylgenistin & $\mathrm{C}_{24} \mathrm{H}_{22} \mathrm{O}_{13}$ & 519.1129 & 519.1133 & -0.8 \\
\hline Isoorientin 2"'"-O-rhamnoside & $\mathrm{C}_{27} \mathrm{H}_{30} \mathrm{O}_{15}$ & 595.1652 & 595.1657 & -0.8 \\
\hline
\end{tabular}


Table 1. Cont.

\begin{tabular}{|c|c|c|c|c|}
\hline Putative Metabolite Identification & Molecular Formula & $\begin{array}{c}{[\mathrm{M}+\mathrm{H}]^{+}} \\
\text {Measured }\end{array}$ & $\begin{array}{c}{[\mathbf{M}+\mathbf{H}]^{+}} \\
\text {Theoretical }\end{array}$ & $\begin{array}{c}\text { Mass Accuracy } \\
\text { (ppm) }\end{array}$ \\
\hline Rutin & $\mathrm{C}_{27} \mathrm{H}_{30} \mathrm{O}_{16}$ & 611.1588 & 611.1607 & -3.0 \\
\hline Narcissin & $\mathrm{C}_{28} \mathrm{H}_{32} \mathrm{O}_{16}$ & 625.1747 & 625.1763 & -2.6 \\
\hline Robinin & $\mathrm{C}_{33} \mathrm{H}_{40} \mathrm{O}_{19}$ & 741.2209 & 741.2236 & -3.6 \\
\hline Flavonoid-7-O-glycosides & $\mathrm{C}_{33} \mathrm{H}_{40} \mathrm{O}_{20}$ & 757.2168 & 757.2186 & -2.3 \\
\hline $\begin{array}{c}\text { Flavonoid-7-O-glycosides } \\
\text { Lipids }\end{array}$ & $\mathrm{C}_{34} \mathrm{H}_{42} \mathrm{O}_{20}$ & 771.2316 & 771.2342 & -3.4 \\
\hline $\begin{array}{c}\text { Jasmonic acid } \\
(9 Z, 12 Z, 15 Z) \text {-octadeca-9,12,15-trien-6- }\end{array}$ & $\mathrm{C}_{12} \mathrm{H}_{18} \mathrm{O}_{3}$ & 211.1331 & 211.1328 & 1.4 \\
\hline $\begin{array}{l}\text { ynoic } \\
\text { acid }\end{array}$ & $\mathrm{C}_{18} \mathrm{H}_{26} \mathrm{O}_{2}$ & 275.2003 & 275.2005 & -0.7 \\
\hline $\begin{array}{l}\text { 13S-Hydroxy-9Z,11E,15Z- } \\
\text { octadecatrienoic } \\
\text { acid }\end{array}$ & $\mathrm{C}_{18} \mathrm{H}_{28} \mathrm{O}_{2}$ & 277.2153 & 277.2162 & -3.2 \\
\hline Linolenic acid & $\mathrm{C}_{18} \mathrm{H}_{31} \mathrm{O}_{2}$ & 279.2318 & 279.2318 & 0.0 \\
\hline 15-Methylhexadecasphinganine & $\mathrm{C}_{17} \mathrm{H}_{37} \mathrm{NO}_{2}$ & 288.2890 & 288.2897 & -2.4 \\
\hline $12,13(\mathrm{~S})-\mathrm{EOT}$ & $\mathrm{C}_{18} \mathrm{H}_{28} \mathrm{O}_{3}$ & 293.2108 & 293.2111 & -1.0 \\
\hline 12-OPDA & $\mathrm{C}_{18} \mathrm{H}_{28} \mathrm{O}_{3}$ & 293.2108 & 293.2111 & -1.0 \\
\hline 10,13-Nonadecadiynoic acid & $\mathrm{C}_{19} \mathrm{H}_{30} \mathrm{O}_{2}$ & 291.2320 & 291.2318 & 0.7 \\
\hline OPC- $8: 0$ & $\mathrm{C}_{18} \mathrm{H}_{30} \mathrm{O}_{3}$ & 295.2266 & 295.2267 & -0.3 \\
\hline 13-HPOT & $\mathrm{C}_{18} \mathrm{H}_{30} \mathrm{O}_{4}$ & 311.2213 & 311.2216 & -1.0 \\
\hline Terpenes & & & & \\
\hline Soyasaponin III & $\mathrm{C}_{42} \mathrm{H}_{68} \mathrm{O}_{14}$ & 797.4641 & 797.4681 & -5.0 \\
\hline Soyasaponin II & $\mathrm{C}_{47} \mathrm{H}_{76} \mathrm{O}_{17}$ & 913.5127 & 913.5155 & -3.1 \\
\hline Dehydrosoyasaponin I & $\mathrm{C}_{48} \mathrm{H}_{76} \mathrm{O}_{18}$ & 941.5064 & 941.5104 & -4.2 \\
\hline Soyasaponin I & $\mathrm{C}_{48} \mathrm{H}_{78} \mathrm{O}_{18}$ & 943.5243 & 943.5261 & -1.9 \\
\hline Saponin & $\mathrm{C}_{55} \mathrm{H}_{70} \mathrm{O}_{14}$ & 955.4855 & 955.4838 & 1.8 \\
\hline Asiaticoside & $\mathrm{C}_{48} \mathrm{H}_{78} \mathrm{O}_{19}$ & 959.5182 & 959.5210 & -2.9 \\
\hline Cauloside D & $\mathrm{C}_{53} \mathrm{H}_{86} \mathrm{O}_{22}$ & 1075.5636 & 1075.5683 & -4.4 \\
\hline Jujuboside B & $\mathrm{C}_{52} \mathrm{H}_{84} \mathrm{O}_{21}$ & 1045.5540 & 1045.5547 & -0.7 \\
\hline Primulasaponin & $\mathrm{C}_{53} \mathrm{H}_{86} \mathrm{O}_{22}$ & 1105.5715 & 1105.5789 & -6.7 \\
\hline
\end{tabular}

As shown in Figure 3, MolNetEnhancer provided the putative chemical classification of compounds detected from the control plants and inoculated with P. pachyrhizi and combined in the molecular network (Supplementary Figure S5), such as flavonoids, isoflavonoids, lipids, fatty acyls, terpenes, carboxylic acids, and others. The significantly regulated metabolites were assigned to the chemical classification to which they belong (Supplementary Table S1). Metabolites derived from phenylpropanoids, such as flavonoids and isoflavonoids, were up-regulated, while terpenes were down-regulated in inoculated plants compared to control plants.

The molecular network obtained provided a total of 191 clusters of interconnected nodes. The cluster represented in Figure 4, containing the spectra of MS/MS de $[\mathrm{M}+\mathrm{H}]^{+}$ $m / z$ 943.522, $[\mathrm{M}+\mathrm{H}]^{+} m / z$ 941.506, $[\mathrm{M}+\mathrm{H}]^{+} m / z$ 797.465, de $[\mathrm{M}+\mathrm{H}]^{+} m / z$ 1105.57, de $[\mathrm{M}+\mathrm{H}]^{+} \mathrm{m} / z 913.511$ putatively identified as soyasaponin I, dehydrosoyasaponin I, soyasaponin III, primulasaponin and soyasaponin II, respectively, highlight the potential of the molecular networking tool for identifying metabolites. These compounds are classified as terpenes, the analogs were separated by $2.016 \mathrm{Da}, 15.995 \mathrm{Da}, 18.011 \mathrm{Da}, 132.041 \mathrm{Da}, 146.058$ $\mathrm{Da}$, and $162.052 \mathrm{Da}$ which are attributed to differences in $\mathrm{H}_{2}, \mathrm{O}, \mathrm{H}_{2} \mathrm{O}, \mathrm{C}_{5} \mathrm{H}_{8} \mathrm{O}_{4}, \mathrm{C}_{6} \mathrm{H}_{10} \mathrm{O}_{4} \mathrm{e}$ $\mathrm{C}_{6} \mathrm{H}_{10} \mathrm{O}_{5}$, respectively. All nodes showed greater spectral similarity, as they were grouped with relatively high cosine scores $(0.88-0.99)$. Using this approach, other ions belonging to the same cluster could be putatively identified. A pie chart layout was also generated using the peak ion area in each sample group (control and inoculated plants) for qualitative assessment. 


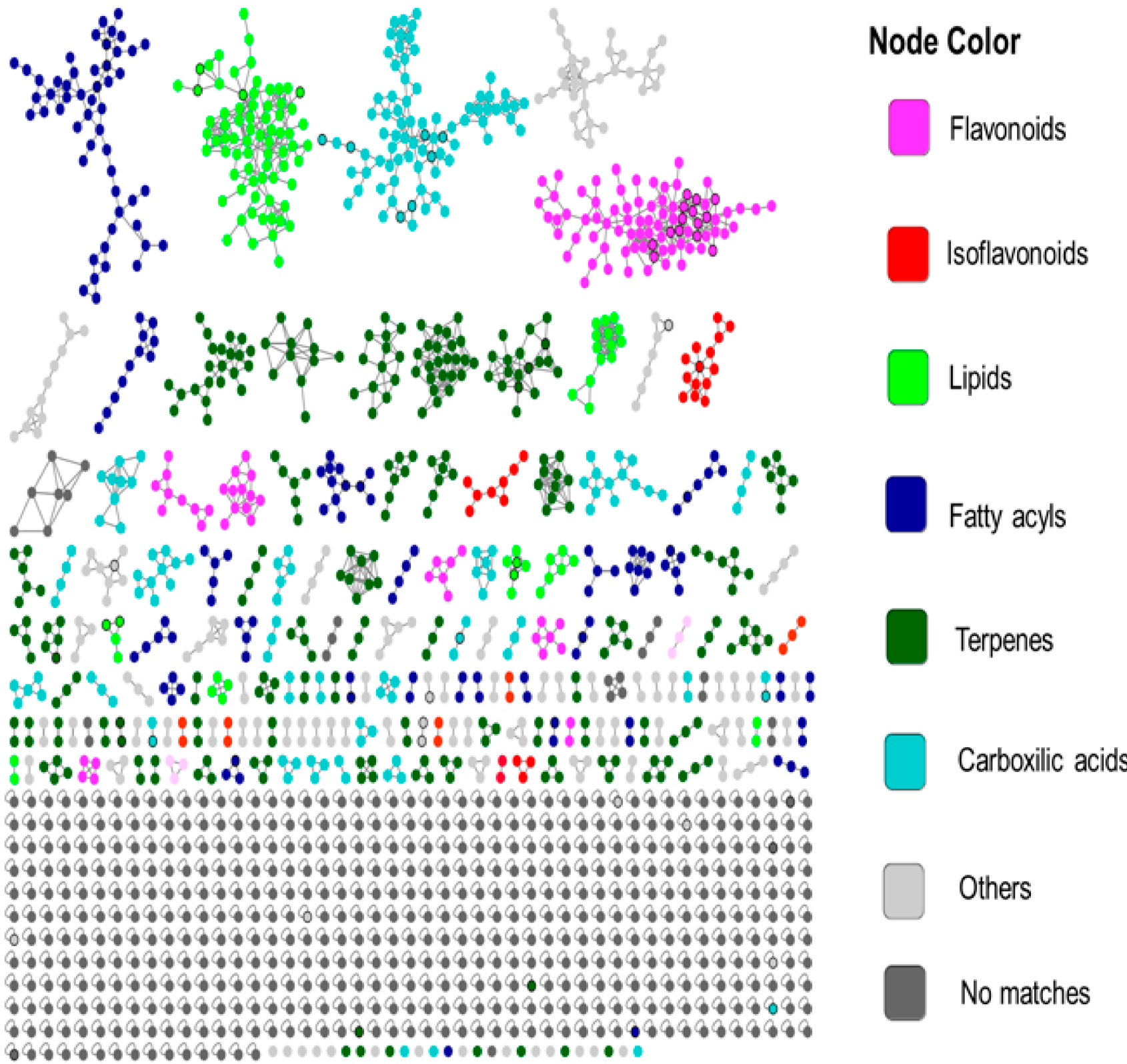

Figure 3. Molecular network of the MS/MS spectra obtained by the analysis of the soybean control plants, or inoculated with P. pachyrhizi colored by 6 chemical class terms selected as indicated in the legend annotated on the molecular network (Supplementary Figure S5) using the MolNetEnhancer. The black bold borders nodes represent the MS/MS spectra that had hits with the spectra of the GNPS libraries. 


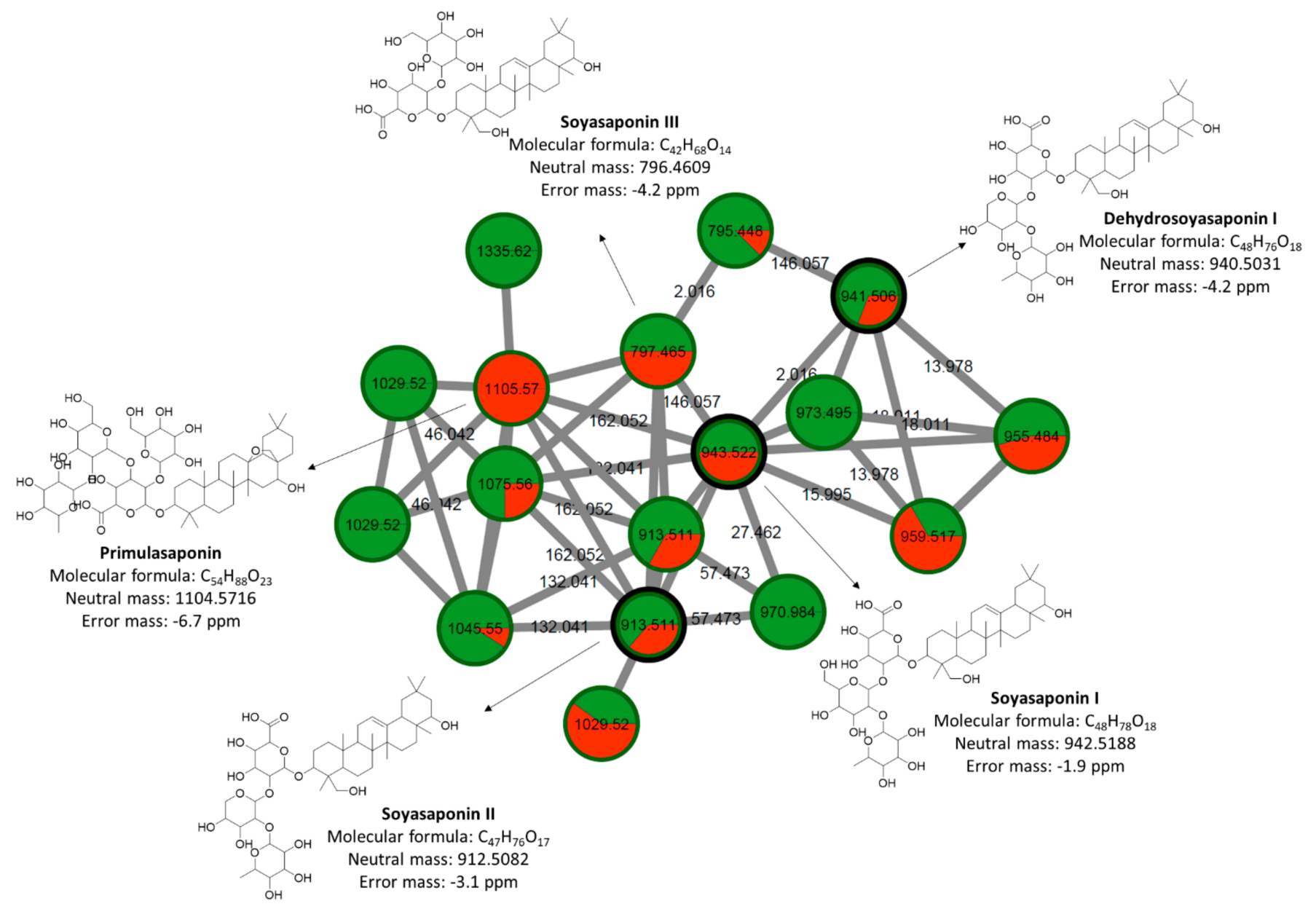

Figure 4. Cluster of terpenes containing triterpene saponins putatively characterized by molecular network obtained from MS/MS data from control plants and inoculated plants with P. pachyrhizi. The edge width represents the cosine score ( 0.88 to 0.99). The edge label represents the mass difference between nodes (2.016 Da, 15.995 Da, 18.011 Da, 132.041 Da, $146.058 \mathrm{Da}$, and $162.052 \mathrm{Da}$ ). The black bold borders nodes represent the MS/MS that had hits with the spectra of the GNPS libraries. The pie chart within each node corresponds to the percentage relative of the metabolite in the sample, green indicates soybean control plants, and red when soybean plants were inoculated with P. pachyrhizi.

\section{Discussion}

Fatty acids and lipids play important roles in different stages of plant-pathogen interactions, including the supply of cellular energy to support metabolic processes, communication between the host and the pathogen, activation, and implementation of plant defense [32]. The lipoxygenase pathway, for example, provides the production of oxylipins, a wide range of metabolites generated by auto-oxidation or enzymatic oxidation of polyunsaturated fatty acids [33].

In our study, polyunsaturated fatty acids were putatively identified as linoleic acid $[\mathrm{M}+\mathrm{H}]^{+} \mathrm{m} / \mathrm{z} 279.2318 ; 13-\mathrm{HPOT}[\mathrm{M}+\mathrm{H}]^{+} \mathrm{m} / \mathrm{z}$ 311.2213; 12,13(S)-EOT $[\mathrm{M}+\mathrm{H}]^{+} \mathrm{m} / \mathrm{z}$ 293.2108; 12-oxo-phytodienoic acid $[\mathrm{M}+\mathrm{H}]^{+} \mathrm{m} / z$ 293.2108, and OPC-8:0 $[\mathrm{M}+\mathrm{H}]^{+} \mathrm{m} / \mathrm{z}$ 295.2266 (Table 1). These compounds are part of the biosynthesis pathway of the phytohormone jasmonic acid, also putatively identified in our study as $[\mathrm{M}+\mathrm{H}]^{+} \mathrm{m} / \mathrm{z} 211.1331$, the invasion by pathogens in the plant activates phospholipase enzymes in the plastid membrane, causing the synthesis of the linoleic acid precursor of the JA biosynthesis process [34]. Positive regulation of the signaling pathway mediated by jasmonic acid has already been reported in studies of resistance against ASR in Medicago truncatula [35] and Arabidopsis thaliana [36], non-host plants of P. pachyrhizi. 
The amino acid phenylalanine is a precursor in the synthesis of phenylpropanoids, which is a group of secondary plant metabolites involved in plant defensive mechanisms against stressors [37-39]. The synthesis of phenylpropanoids is dependent on the enzyme phenylalanine ammonia-lyase (PAL), which catalyzes the conversion of phenylalanine to trans-cinnamic acid and ammonia. The trans-cinnamic acid can be incorporated into many different phenolic compounds, such as p-coumaric acid, caffeic acid, ferulic acid, and sinapic acid.

Transcriptomic studies provide evidence of the role of phenylpropanoid pathway genes in soybean resistance to ASR [40-42]. The increased resistance to specific isolates of P. pachyrhizi in soybean promoted by the Rpp2 gene was compromised when genes, such as the GmPAL1, were silenced. Thus, phenylalanine and PAL might act on the resistance of soybean plants to ASR [43].

A wide range of phenolic compounds is derived from phenylpropanoid compounds such as flavonoids, isoflavonoids, and coumarins, which have been up-regulated in response to infection by P. pachyrhizi (Table 1). Flavonoids and isoflavonoids are phytoalexins, low molecular weight antimicrobial compounds, produced by plants in response to biotic stresses.

The aglycone daidzein $[\mathrm{M}+\mathrm{H}]^{+} \mathrm{m} / z 255.0650$ and its malonyl daidzein conjugate $[\mathrm{M}+\mathrm{H}]^{+} m / z 503.1174$ (Table 1 ) are the main isoflavonoids observed in soybean grains and leaves. Daidzein is a precursor in the metabolic pathway that results in the production of soybean isoflavonoids [44]. In the study previously reported by us, using genotype susceptible to ASR, we observed through qualitative analysis a significant production of flavonoids and isoflavonoids in plants inoculated with P. pachyrhizi, as a plant defense response [24].

Coumarins have antimicrobial and antiviral activities and can act as important actors in the chemical defense strategy in plant-pathogen interactions [45]. Derivatives of the coumarin family have antioxidant and photosensitizing capabilities. Coumarins exposed to specific wavelengths can have nonspecific oxidative damage and cause subsequent death of fungal cells without affecting host cells $[46,47]$. In addition, the phytopathogenic fungus Colletotrichum acutatum, which causes citrus diseases, has been inactivated by the use of photo-treated coumarins and furocoumarins [48].

We identified four coumarins, 7-methoxycoumarin $[\mathrm{M}+\mathrm{H}]^{+} \mathrm{m} / z$ 177.0541; $[\mathrm{M}+\mathrm{H}]^{+}$ $m / z 193.0488$ scopoletin; xanthyletin $[\mathrm{M}+\mathrm{H}]^{+} m / z 229.0857$, and osthole $[\mathrm{M}+\mathrm{H}]^{+} m / z$ 245.1168 (Table 1). Beyer et al., 2019, demonstrated fungistatic activity of coumarin scopoletin against $P$. pachyrhizi [49]. Coumarin was able to suppress the formation of pre-infection streaks and penetration of P. pachyrhizi when sprayed on leaves of Arabidopsis, a non-host plant from ASR [49].

Terpenes are a broad class of compounds spread in plants, and play a role in defending plants against biotic and abiotic stress. Putatively identified triterpenic saponins (Table 1) are a group of phytoanticipins, preformed antimicrobial compounds, which act as chemical barriers against attack by pathogens [50]. Other studies have already reported the antifungal activity of saponins against plant pathogens [51,52]. These compounds have also been identified in the metabolome of the plant of genotype susceptible to ASR. However, the role of saponins against $P$. pachyrhizi is unknown.

\section{Materials and Methods}

\subsection{Plant Preparation}

Soybean (Glycine max) seeds of cultivar were used, PI567025A resistant to ASR (Rpp3 gene) [25], provided by the Germplasm Active Bank (GAB) of Embrapa Soybean. The get seeds (daughters seeds) having homogeneous physiological characteristics were obtained from a single seed (mother seed). The experiment using the seeds was carried out in a greenhouse under the same growth conditions described in Silva et al. 2020 [24]. 


\subsection{Preparation and Inoculation of the P. pachyrhizi}

The spores of P. pachyrhizi were supplied by the Embrapa Soybean Phytopathology Laboratory (Londrina, Parana, Brazil), obtained from cultivar BRS 284 (susceptible standard), with $92 \%$ of germination viability. The inoculum was prepared as described in Silva et al. 2020 [24]. The soybean plants were divided into two groups: 6 control plants and 6 inoculated plants. Each plant was treated individually, by spraying with the fungal spore suspension and the control plants were treated by spraying (just excipients) with aid of a sprinkler bottle. After inoculation plants were submitted to automatic fogging (40 s) every two hours in greenhouse, for a period of $14 \mathrm{~h}$, starting at dusk and kept under the same conditions $\left(\mathrm{T}=28 \pm 2{ }^{\circ} \mathrm{C}\right.$; UR $=70 \% \pm 10 \%$ and photoperiod of $12 \mathrm{~h} / 12 \mathrm{~h}$ (light: dark). Then the control plants were transferred to another greenhouse and kept under the same conditions to avoid contamination. Post-treatment harvesting of the plants was done for both cultivars at 14 days post-inoculation. by cutting off the leaves wrapped in aluminum foil, and immediately immersed in liquid nitrogen and transported to the laboratory. The samples were stored in an ultra-freezer $\left(-80^{\circ} \mathrm{C}\right)$ until the extraction time.

\subsection{Metabolites Extraction}

To evaluate the metabolic profile of the soybean leaves the metabolites were extracted from control plants and inoculated plants using a ternary solvent system (chloroform/methanol/water, 3:1:1 v/v). Soybean leaves were macerated, separately, using liquid nitrogen to preserve the sample during the process. The metabolite extraction was performed as described in Silva et al. 2020 [24]. The samples were concentrated in nitrogen flow and stored in a freezer at $-20^{\circ} \mathrm{C}$ until analysis.

\subsection{UHPLC-ESI-MS/MS Analysis}

The extracts were analyzed using ultra-high-performance liquid chromatography (Shimadzu, Nexera X2, Tokyo, Japan) coupled to a hybrid quadrupole time-of-flight highresolution mass spectrometer (Impac II, Bruker Daltonics Corporation, Bremen, Germany) equipped with an electrospray ionization source. Chromatographic separation was performed with an Acquity UPLC HSS T3 C18 packed with $135 \AA$ pore, $1.7 \mu \mathrm{m}$ particle size, $2.1 \times 100 \mathrm{~mm}$ column (Waters, Billerica, MA, USA) at a flow rate of $0.25 \mathrm{~mL} \mathrm{~min}^{-1}$. Elution gradient was carried out with a binary solvent system consisting of water with $0.1 \%$ formic acid (solvent $\mathrm{A}$ ) and acetonitrile with $0.1 \%$ formic acid (solvent $\mathrm{B}$ ). The initial conditions were $95 \% \mathrm{~A}$ and $5 \% \mathrm{~B}$ held for $1 \mathrm{~min}$, the gradient was applied to $30 \% \mathrm{~A}$ and $70 \% \mathrm{~B}$ at $12 \mathrm{~min}$, and changed to $2 \% \mathrm{~A}$ and $98 \% \mathrm{~B}$ at $20 \mathrm{~min}$ and maintained at $95 \% \mathrm{~A}$ and $5 \% \mathrm{~B}$ for 20 to $25 \mathrm{~min}$ at $40^{\circ} \mathrm{C}$, the final five minutes being intended for reconstitution of the column for the next analysis. The mass spectrometer was calibrated using a solution of sodium formate $\left(10 \mathrm{mmol} \mathrm{L}^{-1}\right.$; isopropanol:water; $\left.1: 1 ; \mathrm{v}-\mathrm{v}\right)$ containing $50 \mu \mathrm{L}$ concentrated formic acid. The capillary voltage was operated in positive ionization modes set at $4500 \mathrm{~V}$, with an endplate offset potential of $-500 \mathrm{~V}$. The dry gas parameters were set to $8 \mathrm{~L} \mathrm{~min}^{-1}$ at $180{ }^{\circ} \mathrm{C}$ with a nebulization gas pressure of 4 bar. Data were collected from $\mathrm{m} / z 50$ to 1800 with an acquisition rate of $5 \mathrm{~Hz}$, and the 5 ions of interest were selected by auto MS/MS scan fragmentation [24].

\subsection{Data Preprocessing and Data Analysis}

The raw data files from UHPLC-ESI(+)-MS/MS were exported as mzXML format and uploaded to the XCMS online software (https: / / xcmsonline.scripps.edu/, accessed date: 10 April 2020). The software was used for feature detection, retention time correction, alignment, automatic integration, and intensity. Parameter settings for XCMS data processing were as follows: Pairwise analysis was performed using centWave for feature detection $(\Delta m / z=10 \mathrm{ppm}$, minimum peak width $=5 \mathrm{~s}$, and maximum peak width $=20 \mathrm{~s})$; for retention time correction and chromatograph alignment was performed with an obiwarp method (profStep $=1$ ), $\operatorname{minfrac}=0.5, \mathrm{bw}=5, \mathrm{mzwid}=0.015$. Statistics analysis was performed with an unpaired parametric $t$-test (Welch $t$-test). 
The processed data file (CSV format) was exported to MetaboAnalyst 3.0 (www. metaboanalyst.ca, accessed date: 10 April 2020) for the multivariate analysis. Prior features were normalized by sum and scaled by the pareto scaling method. Unsupervised multivariate methods Principal Component Analysis (PCA) was performed to determine differences in metabolic profiles between control and inoculated plants. The Partial Least Squares Discriminant Analysis (PLS-DA) supervised method was used to identify altered metabolites between groups.

The model built from PLS-DA analysis was validated using Leave-one-out crossvalidation (LOOCV). The prediction capacity of the model was evaluated by the accuracy parameters $R^{2}$ and $Q^{2}$. Differentially expressed metabolites were selected according to the variable importance in projection (VIP) values $\geq 1$ obtained from the PLS-DA model; $p$-value $\leq 0.001$, from the Welch $t$-test and the maximum ion intensity $\geq 10,000$.

\subsection{Classical Molecular Networking Workflow Description}

A molecular network was created using the online workflow (https://ccms-ucsd. github.io/GNPSDocumentation/) on the GNPS website (http://gnps.ucsd.edu, accessed date: 12 June 2020). The data were filtered by removing all MS/MS fragment ions within $+/-17$ Da of the precursor $m / z$. MS/MS spectra were window filtered by choosing only the top 6 fragment ions in the $+/-50 \mathrm{Da}$ window throughout the spectrum. The precursor ion mass tolerance was set to $0.02 \mathrm{Da}$ and an MS/MS fragment ion tolerance of $0.02 \mathrm{Da}$. A network was then created where edges were filtered to have a cosine score above 0.7 and more than 4 matched peaks. Further, edges between two nodes were kept in the network if and only if each of the nodes appeared in each other's respective top 10 most similar nodes. Finally, the maximum size of a molecular family was set to 100, and the lowest-scoring edges were removed from molecular families until the molecular family size was below this threshold. The spectra in the network were then searched against GNPS' spectral libraries. The library spectra were filtered in the same manner as the input data. All matches kept between network spectra and library spectra were required to have a score above 0.7 and at least 4 matched peaks.

\subsection{MolNetEnhancer Workflow Description for Chemical Class Annotation of Molecular Networks}

To enhance chemical structural information within the molecular network, information from in silico structure annotations from GNPS Library Search, Network Annotation Propagation were incorporated into the network using the GNPS MolNetEnhancer workflow (https:/ / ccms-ucsd.github.io/GNPSDocumentation/molnetenhancer/) on the GNPS website (http:/ / gnps.ucsd.edu, accessed date: 12 June 2020). Chemical class annotations were performed using the ClassyFire chemical ontology.

\section{Conclusions}

Phakopsora pachyrhizi is one of the most challenging pathogens that attack soybean crops, its high genetic variability makes it difficult to control ASR disease, requiring extensive and continuous research to control and combat it. The application of the untargeted metabolomics approach using mass spectrometry combined with chemometric analysis and Global Natural Products Social Molecular Networking platform in the interaction soybean-Phakopsora pachyrhizi was efficient for the knowledge of the expression of metabolites associated with soybean genotype interaction under study and can be used in other plant genotypes soybean, as well as other plant-pathogen interactions. The metabolome of the resistant genotype plant presented secondary metabolites similar to the metabolome of the susceptible genotype plant, showing the same pathways related to the plant's defense responses, such as phenylpropanoids, flavonoids, and isoflavonoids. Besides, this metabolomic study corroborates the transcriptomic studies of ASR already carried out, which report the induction of phenylpropanoid, flavonoid, and isoflavonoid metabolic pathway genes as a defense response to $P$. pachyrhizi, which could assist in research on the 
development of plant genes more resistant to P. pachyrhizi and also in the development of more effective and specific products against the disease.

Supplementary Materials: The following are available online at https:/ /www.mdpi.com/2218-198 9/11/3/179/s1, Figure S1: ASR symptoms, dark spots on the leaf, Figure S2: Reddish-brown lesion type of ASR, Figure S3: Base peak chromatogram (BPC) of analytical replicates after UHPLC-ESI(+)MS/MS analysis. (A) Triplicate plant 1; (B) Triplicate plant 2; (C) Triplicate plant 3; (D) Triplicate plant 4; (E) Triplicate plant 5; (F) Triplicate plant 6. Green BPCs: control plants, red BPCs: inoculated plants, Figure S4: (A) PLS-DA of 18 samples (triplicate of 6 control plants and 6 inoculate plants), green circles correspond to control plant samples $(C)$, red circles correspond to inoculated plant samples (I). The model was built using potential biomarkers obtained by the VIP values. (B) PLSDA permutation validation evaluated by group separation distance (permutation number $=2000$ ). (C) PLS-DA permutation validation by prediction accuracy (permutation number $=2000$ ), Figure S5: Molecular Network of the MS/MS spectra obtained by the analysis of the soybean control plants, or inoculated with P. pachyrhizi. Green nodes correspond to the MS/MS spectra of soybean control plants. Red nodes correspond to the MS/MS spectra of soybean plants inoculated with P. pachyrhizi. Pink nodes correspond to the MS/MS spectra shared spectra in both samples. The edge width represents the cosine score (0.7 to 1.0). The black bold borders nodes represent the MS/MS spectra that had hits with the spectra of the GNPS libraries, Table S1: Metabolites significantly regulated in soy in response to infection by P. pachyrhizi and putative chemical classification.

Author Contributions: E.S., F.C.M.-G., E.N., M.C.M. and E.J.P. conceived the project. E.N. and J.P.d.G. performed the inoculation and greenhouse experiments. E.S. performed extractions and metabolomics analysis and E.J.P. E.S., R.M.d.P., C.P., E.N. and E.J.P. wrote the paper with input from all co-authors. All authors have read and agreed to the published version of the manuscript.

Funding: This project was funded by the grants $401590 / 2014-3-C N P q, 168384 / 2017-5-C N P q$, 155675/2016-8, and 0673/13-CT-Infra-FINEP, 09/2016-Research and Applied Program-Araucária Foundation to Support Scientific and Technological Development of the State of Paraná. This study was financed in part by the Coordination for the Improvement of Higher Education Personnel—Brasil (CAPES)-Finance Code 001.

Institutional Review Board Statement: Not applicable.

Informed Consent Statement: Not applicable.

Data Availability Statement: The data presented in this study are available in article.

Acknowledgments: The authors would like to thank the Brazilian Agricultural Research Corporation (EMBRAPA), the Federal Foundation for the Brazilian Research and Development (FINEP), the Coordination for the Improvement of Higher Education Personnel (CAPES), the National Council for Scientific and Technological Development (CNPQ) and the Complex of Research Support Centers of State University of Maringá (COMCAP-UEM). We would like to thank João Raul Belinato (ApexScience, Brazil) for chemometrics support.

Conflicts of Interest: The authors declare no conflict of interest.

\section{References}

1. Bratton, M.R.; Martin, E.C.; Elliott, S.; Rhodes, L.V.; Collins-Burow, B.M.; McLachlan, J.A.; Wiese, T.E.; Boue, S.M.; Burow, M.E. Glyceollin, a novel regulator of mTOR/p70S6 in estrogen receptor positive breast cancer. J. Steroid Biochem. Mol. Biol. 2015, 150, 17-23. [CrossRef] [PubMed]

2. Hill, J.; Nelson, E.; Tilman, D.; Polasky, S.; Tiffany, D. Environmental, economic, and energetic costs and benefits of biodiesel and ethanol biofuels. Proc. Natl. Acad. Sci. USA 2006, 103, 11206-11210. [CrossRef] [PubMed]

3. Allen, T.W.; Bradley, C.A.; Sisson, A.J.; Byamukama, E.; Chilvers, M.I.; Coker, C.M.; Collins, A.A.; Damicone, J.P.; Dorrance, A.E.; Dufault, N.S.; et al. Soybean yield loss estimates due to diseases in the United States and Ontario, Canada, from 2010 to 2014. Plant Health Prog. 2017, 18, 19-27. [CrossRef]

4. Hossain, M.Z.; Ishiga, Y.; Yamanaka, N.; Ogiso-Tanaka, E.; Yamaoka, Y. Soybean leaves transcriptomic data dissects the phenylpropanoid pathway genes as a defence response against Phakopsora pachyrhizi. Plant Physiol. Biochem. 2018, 132, 424-433. [CrossRef] 
5. Qi, M.; Grayczyk, J.P.; Seitz, J.M.; Lee, Y.; Link, T.I.; Choi, D.; Pedley, K.F.; Voegele, R.T.; Baum, T.J.; Whitham, S.A. Suppression or activation of immune responses by predicted secreted proteins of the soybean rust pathogen Phakopsora pachyrhizi. Mol. Plant Microbe Interact. 2018, 31, 163-174. [CrossRef] [PubMed]

6. Twizeyimana, M.; Hartman, G.L. Sensitivity of Phakopsora pachyrhizi isolates to fungicides and reduction of fungal infection based on fungicide and timing of application. Plant Dis. 2017, 101, 121-128. [CrossRef] [PubMed]

7. Godoy, C.V. Risk and management of fungicide resistance in the Asian soybean rust fungus Phakopsora pachyrhizi. In Fungicide Resistance in Crop Protection: Risk and Management; National Soybean Research Center: Londrina, Brazil, 2011; pp. 87-95, ISBN 9781845939052.

8. $\quad$ Langenbach, C.; Campe, R.; Beyer, S.F.; Mueller, A.N.; Conrath, U. Fighting Asian soybean rust. Front. Plant Sci. 2016, 7, 797. [CrossRef]

9. Childs, S.P.; King, Z.R.; Walker, D.R.; Harris, D.K.; Pedley, K.F.; Buck, J.W.; Boerma, H.R.; Li, Z. Discovery of a seventh Rpp soybean rust resistance locus in soybean accession PI 605823. Theor. Appl. Genet. 2018, 131, 27-41. [CrossRef]

10. Yamanaka, N.; Hossain, M.M. Pyramiding three rust-resistance genes confers a high level of resistance in soybean (Glycine max). Plant Breed. 2019, 138, 686-695. [CrossRef]

11. Murithi, H.M.; Beed, F.; Tukamuhabwa, P.; Thomma, B.P.H.J.; Joosten, M.H.A.J. Soybean production in eastern and southern Africa and threat of yield loss due to soybean rust caused by Phakopsora pachyrhizi. Plant Pathol. 2016, 65, 176-188. [CrossRef]

12. HEIL, M. Induced Systemic Resistance (ISR) Against Pathogens in the Context of Induced Plant Defences. Ann. Bot. 2002, 89, 503-512. [CrossRef]

13. De Coninck, B.; Timmermans, P.; Vos, C.; Cammue, B.P.A.; Kazan, K. What lies beneath: Belowground defense strategies in plants. Trends Plant Sci. 2015, 20, 91-101. [CrossRef] [PubMed]

14. Mhlongo, M.I.; Piater, L.A.; Madala, N.E.; Labuschagne, N.; Dubery, I.A. The Chemistry of Plant-Microbe Interactions in the Rhizosphere and the Potential for Metabolomics to Reveal Signaling Related to Defense Priming and Induced Systemic Resistance. Front. Plant Sci. 2018, 9, 112. [CrossRef] [PubMed]

15. Pedras, M.S.C.; Abdoli, A. Pathogen inactivation of cruciferous phytoalexins: Detoxification reactions, enzymes and inhibitors. RSC Adv. 2017, 7, 23633-23646. [CrossRef]

16. Mazid, M.; Khan, T.A.; Mohammad, F. Role of secondary metabolites in defense mechanisms of plants. Biol. Med. 2011, 3, 232-249.

17. Castro-Moretti, F.R.; Gentzel, I.N.; Mackey, D.; Alonso, A.P. Metabolomics as an Emerging Tool for the Study of Plant-Pathogen Interactions. Metabolites 2020, 10, 52. [CrossRef] [PubMed]

18. Dunn, W.B.; Erban, A.; Weber, R.J.M.; Creek, D.J.; Brown, M.; Breitling, R.; Hankemeier, T.; Goodacre, R.; Neumann, S.; Kopka, J.; et al. Mass appeal: Metabolite identification in mass spectrometry-focused untargeted metabolomics. Metabolomics 2013, 9 , 44-66. [CrossRef]

19. Dettmer, K.; Aronov, P.A.; Hammock, B.D. Mass spectrometry-based metabolomics. Mass Spectrom. Rev. 2007, 26, 51-78. [CrossRef]

20. Glauser, G.; Veyrat, N.; Rochat, B.; Wolfender, J.L.; Turlings, T.C.J. Ultra-high pressure liquid chromatography-mass spectrometry for plant metabolomics: A systematic comparison of high-resolution quadrupole-time-of-flight and single stage Orbitrap mass spectrometers. J. Chromatogr. A 2013, 1292, 151-159. [CrossRef]

21. Worley, B.; Powers, R. Multivariate Analysis in Metabolomics. Curr. Metab. 2013, 1, 92-107. [CrossRef]

22. Saccenti, E.; Hoefsloot, H.C.J.; Smilde, A.K.; Westerhuis, J.A.; Hendriks, M.M.W.B. Reflections on univariate and multivariate analysis of metabolomics data. Metabolomics 2014, 10, 361-374. [CrossRef]

23. Wang, M.; Carver, J.J.; Phelan, V.V.; Sanchez, L.M.; Garg, N.; Peng, Y.; Nguyen, D.D.; Watrous, J.; Kapono, C.A.; Luzzatto-Knaan, T.; et al. Sharing and community curation of mass spectrometry data with Global Natural Products Social Molecular Networking. Nat. Biotechnol. 2016, 34, 828-837. [CrossRef]

24. Silva, E.; da Graça, J.P.; Porto, C.; Martin do Prado, R.; Hoffmann-Campo, C.B.; Meyer, M.C.; de Oliveira Nunes, E.; Pilau, E.J. Unraveling Asian Soybean Rust metabolomics using mass spectrometry and Molecular Networking approach. Sci. Rep. 2020, 10, 1-11. [CrossRef] [PubMed]

25. Miles, M.R.; Frederick, R.D.; Hartman, G.L. Evaluation of Soybean Germplasm for Resistance to Phakopsora pachyrhizi. Plant Health Prog. 2006, 7, 33. [CrossRef]

26. Goellner, K.; Loehrer, M.; Langenbach, C.; Conrath, U.; Koch, E.; Schaffrath, U. Phakopsora pachyrhizi, the causal agent of Asian soybean rust. Mol. Plant Pathol. 2010, 11, 169-177. [CrossRef] [PubMed]

27. Gromski, P.S.; Muhamadali, H.; Ellis, D.I.; Xu, Y.; Correa, E.; Turner, M.L.; Goodacre, R. A tutorial review: Metabolomics and partial least squares-discriminant analysis-a marriage of convenience or a shotgun wedding. Anal. Chim. Acta 2015, 879, 10-23. [CrossRef]

28. Triba, M.N.; Le Moyec, L.; Amathieu, R.; Goossens, C.; Bouchemal, N.; Nahon, P.; Rutledge, D.N.; Savarin, P. PLS/OPLS models in metabolomics: The impact of permutation of dataset rows on the K-fold cross-validation quality parameters. Mol. Biosyst. 2015, 11, 13-19. [CrossRef]

29. Ernst, M.; Kang, K.B.; Caraballo-Rodríguez, A.M.; Nothias, L.F.; Wandy, J.; Chen, C.; Wang, M.; Rogers, S.; Medema, M.H.; Dorrestein, P.C.; et al. Molnetenhancer: Enhanced molecular networks by integrating metabolome mining and annotation tools. Metabolites 2019, 9, 144. [CrossRef] 
30. da Silva, R.R.; Wang, M.; Nothias, L.F.; van der Hooft, J.J.J.; Caraballo-Rodríguez, A.M.; Fox, E.; Balunas, M.J.; Klassen, J.L.; Lopes, N.P.; Dorrestein, P.C. Propagating annotations of molecular networks using in silico fragmentation. PLoS Comput. Biol. 2018, 14, e1006089. [CrossRef]

31. Wandy, J.; Zhu, Y.; Van Der Hooft, J.J.J.; Daly, R.; Barrett, M.P.; Rogers, S. Ms2lda.Org: Web-Based Topic Modelling for Substructure Discovery in Mass Spectrometry. Bioinformatics 2018, 34, 317-318. [CrossRef]

32. Shah, J.; Chaturvedi, R. Lipid Signals in Plant-Pathogen Interactions. In Annual Plant Reviews Online; John Wiley \& Sons, Ltd.: Chichester, UK, 2018; Volume 34, pp. 292-333. ISBN 9781119312994.

33. Wasternack, C.; Feussner, I. The Oxylipin Pathways: Biochemistry and Function. Annu. Rev. Plant. Biol. 2018, 69, 363-386. [CrossRef]

34. Ali, S. Jasmonic Acid Signaling Pathway in Response to Abiotic Stresses in Plants. Int. J. Mol. Sci. 2020, 21, 621. [CrossRef]

35. Ishiga, Y.; Rao Uppalapati, S.; Gill, U.S.; Huhman, D.; Tang, Y.; Mysore, K.S. Transcriptomic and metabolomic analyses identify a role for chlorophyll catabolism and phytoalexin during Medicago nonhost resistance against Asian soybean rust. Sci. Rep. 2015, 5, 1-17. [CrossRef]

36. Loehrer, M.; Langenbach, C.; Goellner, K.; Conrath, U.; Schaffrath, U. Characterization of nonhost resistance of Arabidopsis to the asian soybean rust. Mol. Plant Microbe Interact. 2008, 21, 1421-1430. [CrossRef]

37. Tzin, V.; Galili, G. The Biosynthetic Pathways for Shikimate and Aromatic Amino Acids in Arabidopsis thaliana. Arab. B 2010, 8. [CrossRef]

38. Tohge, T.; Watanabe, M.; Hoefgen, R.; Fernie, A.R. Shikimate and phenylalanine biosynthesis in the green lineage. Front. Plant Sci. 2013, 4, 62. [CrossRef]

39. Vogt, T. Phenylpropanoid Biosynthesis. Mol. Plant 2010, 3, 2-20. [CrossRef] [PubMed]

40. Tremblay, A.; Hosseini, P.; Alkharouf, N.W.; Li, S.; Matthews, B.F. Transcriptome analysis of a compatible response by Glycine max to Phakopsora pachyrhizi infection. Plant Sci. 2010, 179, 183-193. [CrossRef]

41. Morales, A.M.A.P.; O'rourke, J.A.; Van De Mortel, M.; Scheider, K.T.; Bancroft, T.J.; Borém, A.; Nelson, R.T.; Nettleton, D.; Baum, T.J.; Shoemaker, R.C.; et al. Transcriptome analyses and virus induced gene silencing identify genes in the Rpp4-mediated Asian soybean rust resistance pathway. Funct. Plant Biol. 2013, 40, 1029-1047. [CrossRef] [PubMed]

42. Aoyagi, L.N.; Lopes-Caitar, V.S.; de Carvalho, M.C.C.G.; Darben, L.M.; Polizel-Podanosqui, A.; Kuwahara, M.K.; Nepomuceno, A.L.; Abdelnoor, R.V.; Marcelino-Guimarães, F.C. Genomic and transcriptomic characterization of the transcription factor family R2R3-MYB in soybean and its involvement in the resistance responses to Phakopsora pachyrhizi. Plant Sci. 2014, 229, 32-42. [CrossRef]

43. Pandey, A.K.; Yang, C.; Zhang, C.; Graham, M.A.; Horstman, H.D.; Lee, Y.; Zabotina, O.A.; Hill, J.H.; Pedley, K.F.; Whitham, S.A. Functional analysis of the asian soybean rust resistance pathway mediated by Rpp2. Mol. Plant Microbe Interact. 2011, 24, 194-206. [CrossRef]

44. Lygin, A.V.; Li, S.; Vittal, R.; Widholm, J.M.; Hartman, G.L.; Lozovaya, V.V. The importance of phenolic metabolism to limit the growth of Phakopsora pachyrhizi. Phytopathology 2009, 99, 1412-1420. [CrossRef]

45. Stringlis, I.A.; De Jonge, R.; Pieterse, C.M.J. The Age of Coumarins in Plant-Microbe Interactions. Plant Cell Physiol. 2019, 60, 1405-1419. [CrossRef]

46. De Menezes, H.D.; Pereira, A.C.; Brancini, G.T.P.; De Leão, H.C.; Massola Júnior, N.S.; Bachmann, L.; Wainwright, M.; Bastos, J.K.; Braga, G.U.L. Furocoumarins and coumarins photoinactivate Colletotrichum acutatum and Aspergillus nidulans fungi under solar radiation. J. Photochem. Photobiol. B Biol. 2014, 131, 74-83. [CrossRef]

47. Flors, C.; Nonell, S. Light and Singlet Oxygen in Plant Defense Against Pathogens: Phototoxic Phenalenone Phytoalexins. Cheminform 2006, 39, 293-300. [CrossRef]

48. Fracarolli, L.; Rodrigues, G.B.; Pereira, A.C.; Massola Júnior, N.S.; Silva-Junior, G.J.; Bachmann, L.; Wainwright, M.; Bastos, J.K.; Braga, G.U.L. Inactivation of plant-pathogenic fungus Colletotrichum acutatum with natural plant-produced photosensitizers under solar radiation. J. Photochem. Photobiol. B Biol. 2016, 162, 402-411. [CrossRef] [PubMed]

49. Beyer, S.F.; Beesley, A.; Rohmann, P.F.W.; Schultheiss, H.; Conrath, U.; Langenbach, C.J.G. The Arabidopsis non-host defenceassociated coumarin scopoletin protects soybean from Asian soybean rust. Plant J. 2019, 99, 397-413. [CrossRef] [PubMed]

50. Mert-Türk, F. Saponins versus plant fungal pathogens. J. Cell Mol. Biol. 2006, 5, 13-17.

51. Papadopoulou, K.; Melton, R.E.; Leggett, M.; Daniels, M.J.; Osbourn, A.E. Compromised disease resistance in saponin-deficient plants. Proc. Natl. Acad. Sci. USA 1999, 96, 12923-12928. [CrossRef] [PubMed]

52. Zehavi, U.; Ziv-Fecht, O.; Levy, M.; Naim, M.; Evron, R.; Polacheck, I. Synthesis and antifungal activity of medicagenic acid saponins on plant pathogens: Modification of the saccharide moiety and the $23 \alpha$ substitution. Carbohydr. Res. 1993, 244, 161-169. [CrossRef] 